\title{
Electrochemical And Weight Loss Studies Of Extract From Mint As Green Corrosion Inhibitor For Carbon Steel In $\mathrm{H}_{2} \mathrm{SO}_{4}$ Solution
}

\author{
Xiaorong $\mathrm{ZHOU}^{\mathrm{a}}$, Wenfeng WANG ${ }^{\mathrm{b}}$, Jianfen $\mathrm{LI}^{\mathrm{c}}{ }^{*}, \mathrm{Hui}$ FEI ${ }^{\mathrm{d}}$, Guangsen SONG \\ School of Chemical and Environmental Engineering, Wuhan polytechnic university, Wuhan, 430023, \\ China \\ a zxrwhpu@163.com, ${ }^{\mathrm{b}} 1072449612 @ q q . c o m,{ }^{\mathrm{C}}$ lijfen@163.com(corresponding author)
}

Keywords: carbon steel; mint leaves; corrosion inhibitor; electrochemistry; polarization curve; SEM

\begin{abstract}
The inhibitive action of extract from mint leaves (EML) on Q235A hot rolled carbon steel (HRCS) in $0.5 \mathrm{~mol} / \mathrm{L} \mathrm{H}_{2} \mathrm{SO}_{4}$ solution was studied using weight loss measurement, electrochemical polarization and scanning electron microscope (SEM) characterization. The results indicate that the extract functions as a good inhibitor. The inhibition efficiency of EML increases with rise in temperature and concentration. The max value of inhibition efficiency reaches $94.01 \%$ with addition of $320 \mathrm{mg} / \mathrm{L}$ EML inhibitor in $0.5 \mathrm{~mol} / \mathrm{L} \mathrm{H}_{2} \mathrm{SO}_{4}$ solution, at $50{ }^{\circ} \mathrm{C}$. Chemical adsorption of EML components occurs on the surface of carbon steel according to the thermodynamic theoretic analysis. It is shown that the extract of mint leaves acts as a mixed type inhibitor according to the analysis from electrochemical polarization curves. The adsorption of the extract on hot rolled carbon steel obeys Langmuir's adsorption isotherm.
\end{abstract}

\section{Introduction}

Carbon steel is usually used as the raw material for automobile, electronic apparatus or the basement for hot dip galvanizing, plating and coating [1,2]. During the pretreatment process of carbon steel, surface pickling is an important step [3, 4]. Sulfuric acid and hydrochloric acid are most used as the main reagent for pickling [5]. And the former has been used because of small volume, and better mechanical stripping rate of the mill scale, such as FeO, Fe2O3 and Fe3O4, higher temperature tolerance. According to the trend of industrial development, novel corrosion inhibitor for steel pickling should be environmental friendly, non-toxic even better. Corrosion inhibitors extracted from natural products are non-toxic and easily degraded, more and more researchers have been attracted [5].

Mint is a plant wide distributed in America, Europe and Asia. It has long been used as a component of traditional medicine in China or some else countries, for the antiviral, analgesic, antipruritic, anti irritation, cough relieving, sterilization effect, etc[6-7]. And sometimes it is picked up as vegetable in Chinese families because it is fragrant and harEMLss. In the present work, the extract of mint leaves(EML), used as a novel green environmental friendly corrosion inhibitor of carbon steel during acidic pickling, was investigated. The adsorption thermodynamic constants were analyzed.

\section{Experimental Procedures}

Materials. The corrosion test was conducted on Q235A type hot rolled carbon steel (HRCS) plate (size:40 $\mathrm{mm} \times 13 \mathrm{~mm} \times 2 \mathrm{~mm}$, provided by the Hangzhou Guanjie industrial cleaning and water treatment technology Co., Ltd.). The sample plate's composition (in mass fraction) was as follows: C $0.14 \sim 0.22 \%$, Mn $0.30 \sim 0.65 \%, \mathrm{Si} \leq 0.30 \%, \mathrm{~S} \leq 0.05 \%, \mathrm{P} \leq 0.045 \%$, the rest is Fe. All the HRCS plates were pretreated in accordance with the literature[8].

Extract Of Inhibitor. Some mint leaves (commercially available, Mentba spicata L.) were dried to constant mass at $65^{\circ} \mathrm{C}$, and ground into powder. Five gram of the powder was put into a flask 
then $100 \mathrm{ml}$ distilled water was added to ensure the mint leaves powder immersed. The mixture was refluxed at $90^{\circ} \mathrm{C}$ for $2 \mathrm{hrs}$, then filtered under reduced pressure. The solid residue was cleaned twice by small amount distilled water. The filtrate was evaporated and concentrated at $80^{\circ} \mathrm{C}$ to obtain the brown viscous crude product, which was put into the electric heating drying oven at $80^{\circ} \mathrm{C}$ for $24 \mathrm{hrs}$ to get mint leaves extract(EML) in solid membrane form. The solid product was moved out and ground into powder again, 1.1024 gram brown extract powder was obtained, which was put into a desiccator to protect from damp.

Weight loss measurements. Sulfuric acid solutions $(0.5 \mathrm{~mol} / \mathrm{L})$ were prepared with distilled water. EML inhibitor powder was added into the solution and fully dissolved. After pretreatment, three HRCS plates were immersed in the same solution with or without EML for 4 hrs. When corrosion test was finished, sample plates were picked out. After observation of corrosion product on the surface, it was removed with hard rubber and the plates were put into the dilute sodium hydroxide solution (1\% in mass fraction) for neutralization. Then the plates were rinsed by distilled water and ultrasonic washed by anhydrous ethanol and acetone successively. After these proceedings, the plates were dried by natural cold air and stayed in the desiccator for $1 \mathrm{hr}$ for subsequent accurate weighing.

The corrosion rates (CR) are calculated based on the weight loss (WL) measurement as the following equation(Eq. 1):

$\mathrm{CR}=\mathrm{WL} /\left(A_{\mathrm{s}} \times t\right)$.

Where $A_{\mathrm{s}}$ is the sample surface area in $\mathrm{cm}^{2}, t$ is the immersion time in hours (hrs), WL is the weight loss in mg. The inhibition efficiency (IE) is calculated by the equation(Eq. 2) as following[9]:

$\operatorname{IE}(\mathrm{i})=100 \% \times[\mathrm{CR}(0)-\mathrm{CR}(\mathrm{i})] / \mathrm{CR}(0)$.

Where CR(0) is the corrosion rate of HRCS in the sulfuric solution without EML in $\mathrm{mg} \cdot \mathrm{cm}^{-2} \cdot \mathrm{h}^{-1}$; CR(i) is the corrosion rate of HRCS in the sulfuric solution with certain mount EML in $\mathrm{mg} \cdot \mathrm{cm}^{-2} \cdot \mathrm{h}^{-1}$.

Electrochemical polarization measurements. The potentiodynamic polarization curves were measured by CS150 electrochemical workstation (Wuhan Corrtest Instruments Co., Ltd.) with a three electrode cell, consisting of working electrode: HRCS plate with the exposure area of $0.25 \mathrm{~cm}^{2}$, other part were insulated by varnish, auxiliary electrode: a platinum foil electrode (size: $1 \mathrm{~cm} \times 1 \mathrm{~cm}$ ), reference electrode: a saturated calomel electrode (SCE). The scanning speed was $1 \mathrm{mV} / \mathrm{s}$. Each polarization curve was measured at the range of $-150 \mathrm{mV} \sim+150 \mathrm{mV}$ versus the open circuit potential of the working electrode. The solutions contained $0.5 \mathrm{~mol} / \mathrm{L} \mathrm{H}_{2} \mathrm{SO}_{4}$ and different amounts of extract (EML), which were maintained $20^{\circ} \mathrm{C}$. Each potential value was relative to the value of SCE.

The corrosion kinetic parameters $\left(J_{\text {corr }}, b_{\mathrm{a}}, b_{\mathrm{c}}\right)$ could be got by polarization curve fitting from the data of Tafel region, using the software provided by Wuhan Corrtest Instruments Co., Ltd. The inhibition efficiency $(\eta)$ could be calculated by the corresponding equation(Eq. 3)[10]:

$\eta=100 \% \times\left[J_{\text {corr }}(0)-J_{\text {corr }}(i)\right] / J_{\text {corr }}(0)$.

Where $J_{\text {corr }}(0)$ and $J_{\text {corr }}(i)$ are corrosion current densities of the HRCS plates in the solution without and with EML in $\mu \mathrm{A} / \mathrm{cm}^{2}$, respectively.

Scanning Electron Microscopy (SEM) Characterization. The scanning electron microscope (type: S-3000N, Japanese Hitach instrument company) was used. The images of the HRCS plates immersed in $0.5 \mathrm{~mol} / \mathrm{L}$ sulfuric acid solution with and without $160 \mathrm{mg} / \mathrm{L} \mathrm{EML} \mathrm{at} 20^{\circ} \mathrm{C}$ for 4 hrs were obtained to reveal the inhibition effect of EML.

\section{Results And Discussion}

Effect Of Temperature On Inhibition Efficiency. The inhibition efficiency of EML at various temperature was measured in $0.5 \mathrm{~mol} / \mathrm{L} \mathrm{H}_{2} \mathrm{SO}_{4}$ solution contained $320 \mathrm{mg} / \mathrm{L} \mathrm{EML} \mathrm{at} \mathrm{the} \mathrm{range} \mathrm{of}$ $20 \sim 50^{\circ} \mathrm{C}$. The results are shown in Fig.1. It is revealed that the inhibition efficiency rises with temperature increasing, while the range of inhibition efficiency upgrading reduces and reaches the maximum value at $50^{\circ} \mathrm{C}$. This behavior implies that chemical adsorption of EML occurs on the surface of carbon steel [11]. 


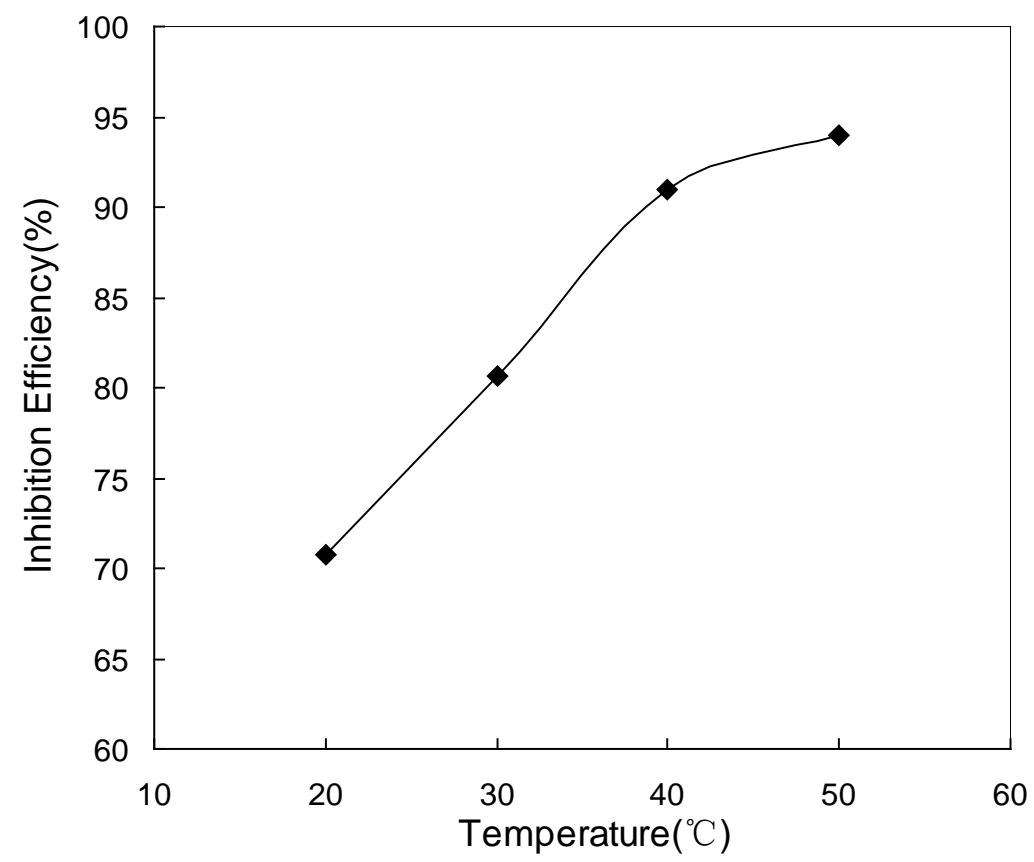

Fig.1 The influence of temperature on inhibition efficiency of EML

Effect Of Inhibitor (EML) Concentration On Inhibition Efficiency. The effect of mint leaves extract (EML) concentration in the $0.5 \mathrm{~mol} / \mathrm{L} \mathrm{H}_{2} \mathrm{SO}_{4}$ solution on the corrosion inhibition efficiency was studied at $50^{\circ} \mathrm{C}$ and shown in Fig.2. The results show that the inhibition efficiency increased rapidly with the concentration of EML in the $0 \sim 40 \mathrm{mg} / \mathrm{L}$, while the trend became less when the concentration exceeds $40 \mathrm{mg} / \mathrm{L}$ and tended to be constant at the concentration of range 160 320 $\mathrm{mg} / \mathrm{L}$, which indicates saturated adsorption. The maximum value of $94.01 \%$ was achieved when the concentration of EML was 320mg/L.

Adsorption Isotherm And Thermodynamic Parameters.The experimental data are fitted according to Langmuir's, Temkin's and Freundlich's adsorption isotherm equations. The results suggest the adsorption of EML on the carbon steel surface obeys the Langmuir adsorption isotherm equation (Eq. 4)[12]:

$c / \theta=1 / K+c$.

Where $c$ is the concentration of EML in $\mathrm{mg} / \mathrm{L}, K$ is the adsorptive equilibrium constant and $\theta$ is the surface coverage degree.

The adsorption enthalpy $(\Delta H)$ of EML on the carbon steel could be calculated according to the Van't Hoff equation(Eq. 5) [12]:

$\ln \{K\}=-\Delta H / R T+$ constant.

Where $\{K\}$ is the value of adsorptive equilibrium constant in $10^{3} \cdot \mathrm{M} \mathrm{L} / \mathrm{mol}, R$ is the molar gas constant $\left(8.314 \mathrm{~J} \cdot \mathrm{mol}^{-1} \cdot \mathrm{K}^{-1}\right)$, and $T$ is the temperature in Kelvin. From the slope $(-\Delta H / R)$ of the line,

$\Delta H$ could be calculated. The standard adsorption free energy could be calculated according to the equation (Eq. 6) as following [8]:

$K=\exp \left(-\Delta G^{\Theta} / R T\right) / 55.5$.

Here, 55.5 is the concentration of water in the solution in $\mathrm{mol} / \mathrm{L}$. Under the measurement conditions, the standard adsorption free energy $\left(\Delta G^{\ominus}\right)$ could be approximately regarded as the adsorption free energy $(\Delta G)$. And the adsorption entropy $(\Delta S)$ could be calculated according to the following thermodynamic basic equation (Eq. 7):

$\Delta S=(\Delta H-\Delta G) / T$. 


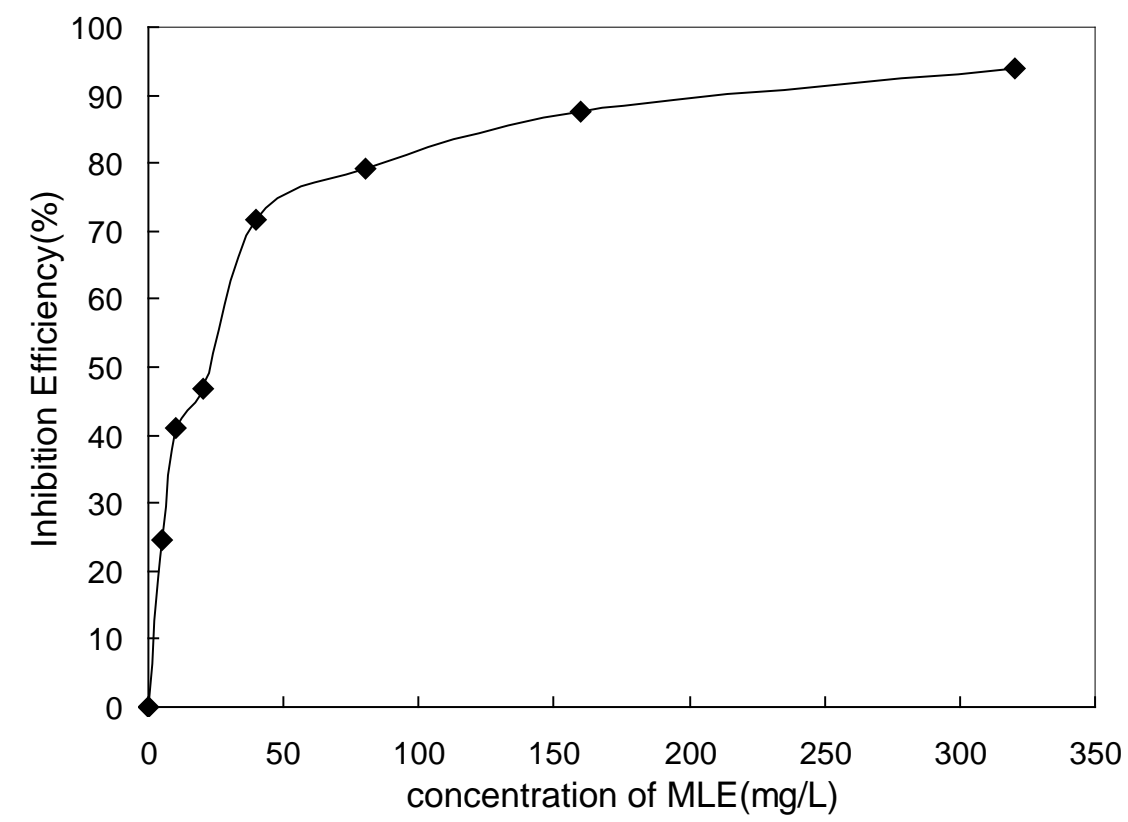

Fig.2 Corrosion inhibition efficiency of mint leaf extract on $\operatorname{HRCS}\left(50^{\circ} \mathrm{C}\right)$

All the adsorption thermodynamic parameters are calculated and shown in Table 1. It is observed that the adsorption enthalpy of EML on carbon steel is $6.443 \mathrm{~kJ} / \mathrm{mol}$, which indicates an endothermic process leading to increase of inhibition performance with temperature. EML, as a mixture of amino acids, flavonoids and carbohydrates, has been measured in previous study by present workgroup. The average molar mass $(M)$ of which should be larger than $100 \mathrm{~g} / \mathrm{mol}$, is used to calculate the $\Delta G$ and $\Delta S$. The data of $\Delta G$ and $\Delta S$ listed in Table 1 are calculated by the value of $100 \mathrm{~g} / \mathrm{mol}$. The value of $\Delta G$ is negative than $-20 \mathrm{~kJ} / \mathrm{mol}$, which suggests the adsorption of EML might be due to chemical adsorption [12].

Table 1 Adsorption thermodynamic parameters

\begin{tabular}{cccc}
\hline$T\left[{ }^{0} \mathrm{C}\right]$ & $\Delta H\left[\mathrm{~kJ} \cdot \mathrm{mol}^{-1}\right]$ & $\Delta G\left[\mathrm{~kJ} \cdot \mathrm{mol}^{-1}\right]$ & $\Delta S\left[\mathrm{~J} \cdot \mathrm{K}^{-1} \cdot \mathrm{mol}^{-1}\right]$ \\
\hline 20 & 6.443 & $\leq-30.119$ & $\geq 124.785$ \\
\hline 30 & 6.443 & $\leq-32.565$ & $\geq 128.739$ \\
40 & 6.443 & $\leq-33.086$ & $\geq 126.291$ \\
50 & 6.443 & $\leq-34.066$ & $\geq 125.415$ \\
\hline
\end{tabular}

Electrochemical Polarization Curves Analysis. The polarization curves of HRCS in 0.5mol/L $\mathrm{H}_{2} \mathrm{SO}_{4}$ solution with various concentrations of EML at $20^{\circ} \mathrm{C}$ are shown in Fig.3. The polarization curves were analyzed by the electrochemical processing software to obtain the electrochemical corrosion parameters of carbon steel, which were listed in Table 2.

From the data in Table 2, it could be found that the corrosion current density $\left(J_{\text {corr }}\right)$ decreases with the increase of EML concentration, which indicates the improvement of inhibitive performance. The inhibition efficiency of EML on HRCS is calculated by Eq. 3 and listed in Table 2. It is shown that the inhibition efficiency of EML reaches $77.01 \%$ at 320mg/L.The value of inhibition efficiency is consistent with the results shown in Fig.1. On the other hand, both the anodic and the cathodic Tafel slopes ( $b a, b c$ ) change obviously with addition of EML, while change little with the concentration increasing, which indicates EML as a mixed type inhibitor for HRCS in $0.5 \mathrm{~mol} / \mathrm{L}$ $\mathrm{H}_{2} \mathrm{SO}_{4}$ solution. This is confirmed by the the value of $\Delta E_{\text {corr }}$ between in the absence and presence of EML, which were less than $85 \mathrm{mV}$ [13]. 


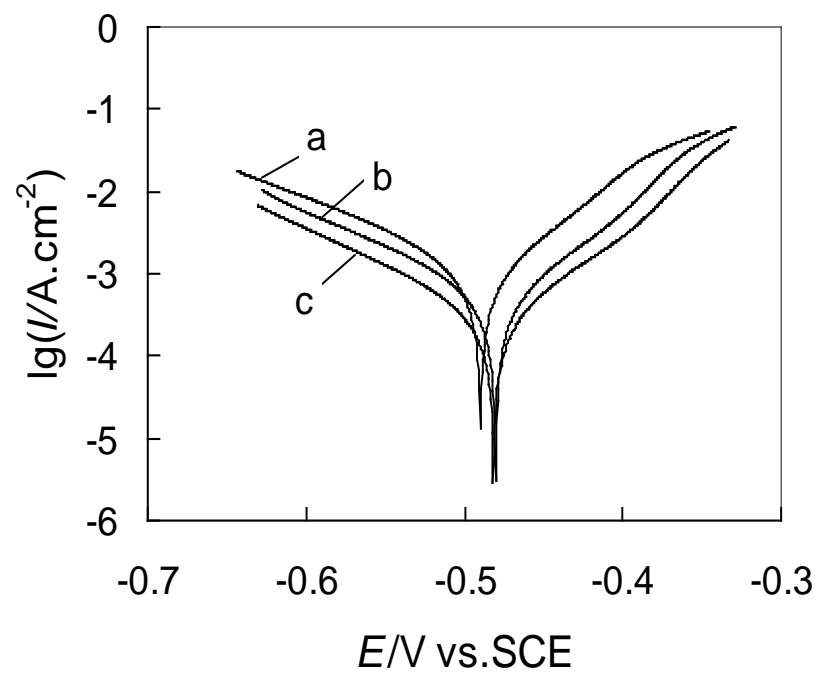

Fig.3 Polarization curves of HRCS in different solution $\left(20^{\circ} \mathrm{C}\right.$ ) (curve a: without EML; curve b: $160 \mathrm{mg} / \mathrm{L}$; curve c: 320mg/L)

Table 2 Electrochemical corrosion parameters of HRCS and IE of EML(20 $\left.{ }^{\circ} \mathrm{C}\right)$

\begin{tabular}{cccccc}
\hline & $b a[\mathrm{mV} / \mathrm{dec}]$ & $b c[\mathrm{mV} / \mathrm{dec}]$ & $J_{\text {corr }}\left[\mu \mathrm{A} / \mathrm{cm}^{2}\right]$ & $E_{\text {corr }}[\mathrm{V}]$ & $\eta[\%]$ \\
\hline Without EML & 81.98 & 127.9 & 1165.0 & -0.4899 & - \\
160mg/L EML & 70.06 & 108.0 & 462.0 & -0.4803 & 60.36 \\
320mg/L EML & 72.66 & 103.9 & 267.6 & -0.4816 & 77.01 \\
\hline
\end{tabular}

Scanning Electron Microscope (SEM) Characterization. The results of SEM images $(\times 2000)$ of HRCS after having been immersed in corrosion solution without (Fig.4a) and with EML (Fig.4b) for $4 \mathrm{hrs}$ at $20^{\circ} \mathrm{C}$, respectively, are shown in Fig.4. It is observed from Fig.4a that the surface morphology of HRCS in the absence of EML is rough with remarkable crisscross cracks. The surface rough degree of HRCS with addition of 160mg/L EML (Fig.4b) decreases obviously, due to the inhibitive effect depend on the adsorption of inhibitor molecules on the surface of metal.

\section{Conclusions}

The extract from mint leaves (EML) is an eco-friendly inhibitor for the corrosion of hot rolled carbon steel (HRCS) in $0.5 \mathrm{~mol} / \mathrm{L} \mathrm{H}_{2} \mathrm{SO}_{4}$ solution. The inhibition efficiency of EML increases with the increase of concentration and temperature. The adsorption of EML inhibitor on HRCS surface obeys Langmuir isotherm, which is an endothermic and spontaneous process due to chemical adsorption. Electrochemical polarization curves reveal that EML acts as a mixed type inhibitor for HRCS. The result of SEM analysis is in agreement with the results from analysis of electrochemical polarization measurements and weight loss measurements.

\section{Acknowledgements}

This work has been financially supported by the Hubei Province Youth Educational Fund (No.Q20131703), Natural Science Foundation of Hubei Province (No.2014CFB890) and Wuhan Polytechnic University College Student Research Project. 

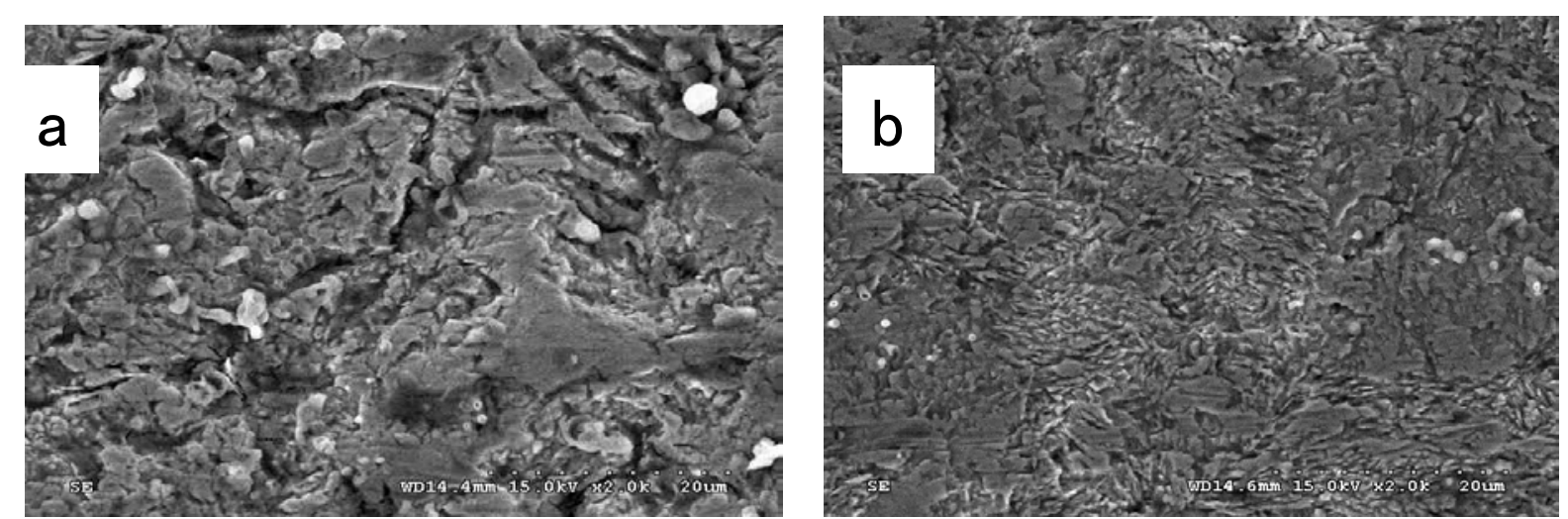

Fig. 4 SEM images of HRCS immersed in corrosion solution for $4 \mathrm{hrs}$ (a): $0.5 \mathrm{~mol} / \mathrm{L} \mathrm{H}_{2} \mathrm{SO}_{4}$ solution , (b):0.5mol/ $\mathrm{L} \mathrm{H}_{2} \mathrm{SO}_{4}$ solution with $160 \mathrm{mg} / \mathrm{L} \mathrm{EML}$

\section{References}

[1] S.Fujita, D.Mizuno, Corrosion and corrosion test methods of zinc coated steel sheets on automobiles,Corros.Sci. 49(2007) 211-219.

[2] G.Chen, L.Mei, M.Zhang, et al,Research on key influence factors of laser overlap wielding of automobile body galvanized steel, Opt.Laser.Technol. 45(2013) 726-733.

[3] Y.He, T.Jia, X.Liu, et al, Hot-dip Galvanizing of Carbon Steel after Cold Rolling with Oxide Scale and Hydrogen Descaling, J.Iron.Steel.Res.Int. 21 (2014) 222-226.

[4] A.A.Mouayd, M.E.Orazem, E.M.M.Sutter, et al, Contribution of electrochemical dissolution during pickling of low carbon steel in acidic solutions,Corros.Sci. 82(2014)362-368.

[5] R.Solmaz. Investigation of corrosion inhibition mechanism and stability of Vitamin B1 on mild steel in 0.5M HCl solution, Corros.Sci. 81(2014)75-84.

[6] S.Škrovánková, L.Mišurcová, L.Machů, Chapter Three-Antioxidant Activity and Protecting Health Effects of Common Medicinal Plants, Adv. Food Nut.Res.67(2012)75-139.

[7] R.Scherer, M.F.Lemos, M.F.Lemos, et al, Antioxidant and antibacterial activities and composition of Brazilian spearmint(Mentha spicata L.), Ind.Crops Prod. 50(2013)408-413.

[8] M.Znini, L.Majidi, A.Bouyanzer, et al, Essential oil of Salvia aucheri mesatlantica as a green inhibitor for the corrosion of steel in 0.5 $\mathrm{M} \mathrm{H}_{2} \mathrm{SO}_{4}$, Arab.J.Chem. 5(2012) 467-474.

[9] P.C.Okafor, M.E.Ikpi, I.E.Uwah, et al, Inhibitory action of Phyllanthus amarus extract on the corrosion of mild steel in acidic media, Corros.Sci. 50(2008)2310-2317.

[10] E.McCafferty, N. Hackerman, Double layer capacitance of iron and corrosion inhibition with polymethylene diamines, J.Electrochem.Soc. , 119(1972)146-154.

[11] F.Bentiss, M.Traisnel, N.Chaibi, et al, 2,5-Bis(n-methoxyphenyl)-1,3,4-oxadiazoles used as corrosion inhibitors in acidic media: correlation between inhibition efficiency and chemical structure, Corros.Sci. 44(2002)2271-2289.

[12] X.Li, G.Mu, Tween-40 as corrosion inhibitor for cold rolled steel in suphuric acid: Weight loss study, electrochemical characterization, and AFM, Appl.Surf.Sci. 252(2005)1254-1265.

[13] A.O.Yuce, B.D.Mert, G. Kardas, et al., Electrochemical and quantum chemical studies of 2-amino-4-methyl-thiazole as corrosion inhibitor for mild steel in $\mathrm{HCl}$ solution, Corros.Sci.83(2014)310-316. 